\title{
O LUGAR DA ÁFRICA NA POLÍTICA EXTERNA BRASILEIRA APÓS $2003^{1}$
}

\section{The Place of Africa in Brazil's Foreign Policy After 2003}

Giovanna de Neiva Barriviera²

\section{Introdução}

Desde 2003 as relações entre o Brasil e países do continente africano têm passado por uma nova fase de aproximação. As relações historicamente pendulares entre Brasil e países africanos, caracterizadas por períodos de aproximação e relativo afastamento, hoje dão lugar a relações mais sólidas, estreitas e de médio e longo prazo. Após 2003, houve uma reorganização interna do Itamaraty em relação à África, o ex- Presidente Luiz Inácio Lula da Silva visitou o continente onze vezes ao longo de seus oito anos à frente do executivo federal, enquanto Dilma o fez cinco vezes em seus primeiros quatro anos à frente do poder executivo federal; houve um crescimento significativo no orçamento de cooperação entre o Brasil e países africanos, além do crescimento significativo do número de empresas brasileiras nesse continente, bem como do volume de comércio entre o Brasil e países africanos.

Além do reconhecimento, por parte dos formuladores da política externa brasileira, da importância do continente africano para a inserção estratégica do Brasil no início do século XXI, o crescimento econômico continuado que esses países têm vivenciado é outro fator relevante. Enquanto diversos países passam por crises econômicas e estagnação de crescimento, as economias africanas passam por um processo de dinamização e expansão que abre possibilidade para investimentos e parcerias em diversos setores com grande perspectiva de rentabilidade. Assim, o continente africano tem assumido um papel de maior destaque dentro da política externa brasileira. Ainda que não sejam os principais parceiros comerciais do Brasil, os países africanos têm se mostrado uma importante fronteira de negócios para empresas brasileiras, além de representar um importante campo de atuação brasileira no âmbito das relações e da cooperação Sul-Sul.

\footnotetext{
${ }^{1}$ Uma versão preliminar deste artigo foi apresentada durante o VII Seminário Nacional de Sociologia e Política da Universidade Federal do Paraná em maio de 2016. Agradeço as contribuições dos comentadores que foram de grande importância para esta versão expandida do mesmo. Agradeço também as mestrandas Luana Fisher Bassegio e Michelle Gallera Dias pela colaboração na coleta dos dados analisados no decorrer do artigo.

${ }^{2}$ Graduada em Ciências Sociais pela UFPI, mestre em Ciência Política pela UFPI, doutoranda em Ciência Política pela UFRGS. (gibarriviera@gmail.com).
} 
Diante do exposto, cabe analisar o lugar da África na política externa brasileira após 2003. Argumentase aqui que há um fortalecimento significativo e consolidação do continente africano em uma posição de destaque dentro da política externa brasileira após 2003. Para tanto, o presente artigo se estrutura em quatro seções. Na primeira seção trata, de forma breve, sobre o histórico das relações entre Brasil e África desde o império até o fim do governo de Fernando Henrique Cardoso em 2002. A segunda seção busca analisar os rumos da política externa brasileira durante o governo Lula (2003-2010) e os indicativos do fortalecimento do lugar da África na política externa brasileira. A terceira analisa as relações afro-brasileiras durante o governo de Dilma Rousseff. A quarta e última seção trata das conclusões.

\section{Um breve histórico das relações afro-brasileiras}

Os primeiros contatos afro-brasileiros se dão ainda no seio do império colonial português. De acordo com Visentini (2013, p.81), devido ao tráfico negreiro que perdurou de 1538 a 1850 "milhões de africanos foram trazidos como escravos para o Brasil, fazendo com que a europeização das novas terras fosse acompanhada por sua africanização”. Ainda que o relacionamento afro-brasileiro seja tão antigo quanto a presença portuguesa no Brasil, este relacionamento é caracterizado por períodos de aproximação e afastamento.

O primeiro período de afastamento se deu logo após o processo de independência. Devido às pressões de Portugal durante as negociações para o reconhecimento do Brasil como Estado independente e as pressões do governo inglês para a restrição do tráfico negreiro, principal atividade que ligava o Brasil ao continente africano, aliado aos conflitos com seus vizinhos para o estabelecimento das fronteiras do estado recémindependente, as autoridades de política exterior do Brasil voltaram sua atenção ao contexto regional e aos conflitos com seus vizinhos em uma política externa focada na Bacia Platina. Porém, do ponto de vista comercial, o Brasil continuou relacionando-se intensamente com o continente africano, relação que só irá entrar em verdadeiro declínio com o fim do tráfico negreiro em 1850 (PENNA FILHO E LESSA, 2007).

Com o fim do tráfico negreiro no Atlântico Sul, período que "coincidiu com o início da expansão colonialista europeia na África” (VISENTINI, 2013, p. 89), há um segundo afastamento entre o Brasil e o continente africano, perdurando por cerca de um século (PENNA FILHO E LESSA, 2007). Penna Filho e Lessa (2007) apontam dois fatores que contribuíram para esse afastamento. O primeiro é a penetração europeia no continente africano e o sistema colonial lá implantado, que, por sua lógica, barrava os contatos entre as colônias africanas e o mundo. O segundo fator é a política de imigração que privilegiava populações europeia em meados do século XIX e a tentativa de "apagar da memória nacional as relações com a África, sobretudo o legado escravo africano deixado no Brasil por séculos de trabalho forçado” (PENNA FILHO E LESSA, 2007 p.59), em uma tentativa de "branqueamento da população".

Até a década de 1960, a política externa brasileira estava focada nos relacionamentos com a América e Europa, negligenciando quase totalmente os continentes africano e asiático. O modelo de desenvolvimento acelerado adotado por Kubitschek nos anos 1950 privilegiou o relacionamento com países desenvolvidos para financiar o desenvolvimento nacional. Esse alinhamento resultou no apoio brasileiro ao colonialismo francês 
no continente africano, uma vez que os investimentos franceses no Brasil eram considerados de grande importância para a estratégia de desenvolvimento adotada no período (PENNA FILHO E LESSA, 2007).

No entanto, não foi apenas o apoio ao colonialismo francês no continente africano que se mostrou prejudicial ao Brasil. $\mathrm{O}$ apoio ao colonialismo português também representou um entrave ao estabelecimento de relações com os países recém-independentes no continente.

As relações entre Brasil e Portugal, dado o seu marcante caráter baseado no sentimentalismo, interferiram intensamente nas relações entre o Brasil e o continente africano, principalmente em virtude da postura brasileira diante do colonialismo português. Foram afetadas não apenas as relações com as colônias de Portugal, mas também com a maior parte do mundo africano, dado que o sentimento de solidariedade entre os países daquele continente possibilitou uma ação coordenada, como bloco, nos organismos internacionais, onde o Brasil era acusado, ou suspeito, de cooperar com o colonialismo luso (PENNA FILHO E LESSA, 2007, p.64).

Além da baixa receptividade por parte dos países africanos à política externa brasileira, o Tratado de Amizade e Consulta ${ }^{3}$ assinado em 1953 entre os governos do Brasil e de Portugal, além de prever consulta mútua sempre que os interesses internacionais de ambas as partes fossem em comum (PENNA FILHO E LESSA, 2007), bloqueava "o acesso brasileiro às províncias ultramarinas, notadamente africanas, ao mesmo tempo que Portugal obtinha do Brasil a garantia de que as relações especiais entre ambos permaneceriam” (PENNA FILHO E LESSA, 2007, p. 65).

Durante a primeira metade do século XX, o comércio afro-brasileiro estava restrito, quase em sua totalidade, à África do Sul (VISENTINI, 2013). Esse fato, aliado ao apoio brasileiro ao colonialismo português no continente, representou um empecilho para o desenvolvimento de uma política africana brasileira já que a maioria dos Estados africanos não aceitavam Portugal e África do Sul, o primeiro por seu colonialismo e o segundo por seu regime de Apartheid que reproduzia os mecanismos de dominação racial do colonialismo, além de exercer dominação sobre o território que hoje corresponde à Namíbia (PENNA FILHO E LESSA, 2007), com isso, muitos países africanos apresentaram resistência ${ }^{4}$ ao estabelecimento de relações com o Brasil.

“Em 1960, o Ano Africano, dezessete países se tornaram independentes, com o Brasil adotando uma política meramente protocolar. Foi preciso o desencadeamento da Política Externa Independente, no governo Jânio Quadros para que a África adquirisse importância para a diplomacia brasileira” (VISENTINI, 2013, p.89). A Política Externa Independente de Quadros e João Goulart transformou a perspectiva das relações entre Brasil e Portugal, em especial sobre as questões coloniais que representavam o pano de fundo das relações entre os dois países no pós-Segunda Guerra Mundial, e até o golpe de Estado de 1964, a política externa brasileira buscou reverter o apoio dado ao colonialismo português (PENNA FILHO E LESSA, 2007).

Naquele momento, as elites brasileiras aspiravam uma participação na emergente multipolaridade, com a ideia subjacente do Brasil como uma potência emergente. Aproximar-se dos países africanos foi uma questão de princípios e de interesses: o objetivo era promover a solidariedade entre os países do Sul e, ao

\footnotetext{
${ }^{3}$ O Tratado de Amizade e Consulta entre o Brasil e Portugal pode ser consultado na íntegra no sítio http://dai-mre.serpro.gov.br/atosinternacionais/bilaterais/1953/b_50/

${ }^{4} \mathrm{O}$ caso mais emblemático de resistência ao estabelecimento de relações com o Brasil é o moçambicano. Após a independência de Moçambique, o governo da Frelimo (Frente de Libertação de Moçambique) acusou o governo brasileiro de não apoiar a luta do país por independência e sim o regime colonial português.
} 
mesmo tempo, aumentar a capacidade de influência do Brasil nos assuntos globais, a partir de uma diversificação de suas relações externas, tanto políticas como econômicas (LECHINI, 2008, p.57).

Segundo Lechini (2008), foi durante o governo de Jânio Quadros que se implementou pela primeira vez uma estratégia global para a África. A Política Externa Independente dará a base, para que na década de 1970, inicie o período que Lechini (2008) chama de “os anos dourados da política africana do Brasil”.

O primeiro governo militar, liderado pelo Marechal Humberto Castelo Branco, durante 1964-1967, marcou o revés da Política Externa Independente de seus antecessores. Buscando acabar com a politização da PEI, Castelo Branco abandonou o discurso terceiro mundista, ponto central na PEI, optando por uma estratégia de alinhamento automático com os Estados Unidos e deu ênfase ao tema da segurança coletiva, condenando os movimentos de libertação nacional de cunho marxista (VISENTINI, 2013; LECHINI, 2008). Seu sucessor, Costa e Silva (1967-1969) não promoveu ações de aproximação com o continente africano (VISENTINI, 2013). Foi durante o governo Médici (1969-1974) que se iniciou a reaproximação com a África. Sob a lógica da Diplomacia do Interesse Nacional e o país passando por seu "milagre econômico", o continente africano mostrou-se como fornecedor de petróleo e outras matérias-primas, além de mercado consumidor para a indústria nacional em rápida expansão. Assim, foram firmados diversos acordos comerciais, culturais e de cooperação técnica com o continente africano (VISENTINI, 2013).

O governo de Ernesto Geisel (1974-1979) marcou o aprofundamento das relações afro-brasileiras. Sob a égide do Pragmatismo Responsável, iniciaram-se dez anos de ótimas relações com o continente africano (LECHINI, 2008). O governo Geisel coincidiu com o fim do regime salazarista e do colonialismo português o que representou um novo horizonte de atuação brasileira no continente. Segundo Penna Filho e Lessa (2007, p.69), “o Brasil só conseguiu sair do seu estado de ambiguidade com relação à África após o colapso do colonialismo português, esgotado definitivamente com a Revolução dos Cravos e o fim do regime salazarista em 1974".

\footnotetext{
A aproximação em relação à África, ou melhor, a reaproximação, como definem Fernando Albuquerque Mourão e Henrique Altemani de Oliveira, foi consequência de um processo com alguns momentos emblemáticos. Iniciou-se com os países africanos de língua inglesa e francesa para alcançar depois os de língua portuguesa. O Brasil desenvolveu diferentes ações através de uma política incrementalista que foi se refletindo na densidade das vinculações e que se evidenciou no perfil e na quantidade de visitas, na assinatura de variados acordos de cooperação e no aumento das relações comerciais (LECHINI, 2008, p.57).
}

A reaproximação com a África, além de seu aspecto político, também possuiu uma dimensão comercial. Segundo Lechini (2008), houve um aumento significativo nas exportações brasileiras para a África, além de uma diversificação de destinos e mudança da composição das exportações.

No começo do governo Médici, os destinos das vendas eram o norte da África e a África do Sul. Mas, durante o período Geisel, a África do Sul perdeu peso nas exportações enquanto o Gabão, Congo e Angola começaram a ter uma participação maior. No entanto, não se tratou apenas de uma mudança de parceiros, mas também de uma profunda alteração na composição das exportações brasileiras para a África: elas passaram a ser predominantemente manufaturados (LECHINI, 2008, p.61). 
A Diplomacia do Universalismo de João Baptista Figueiredo (1979-1985) manteve a aproximação com o continente africano e expandiu a cooperação entre as duas margens do Atlântico. A primeira visita oficial ${ }^{5}$ de um presidente brasileiro ao continente africano se deu durante o governo Figueiredo, após quase quatro séculos de relacionamento afro-brasileiro. O comércio cresceu continuamente, programas de cooperação em diversas áreas foram firmados e houve também o aumento significativo do número de representações diplomáticas dos países africanos em Brasília (VISENTINI, 2013) e de visitas de chefes de Estado e chanceleres africanos durante o mesmo período. O governo João Baptista Figueiredo foi o último do período militar sendo sucedido por José Sarney (1985-1990). Ainda Sarney que tenha mantido o alto-perfil nas relações afrobrasileiras, as dificuldades econômicas que afligiam tanto o Brasil quanto a África aliado as adversidades do sistema internacional daquele momento, contribuíram para a inflexão nas relações afro-brasileiras dos anos 1990 (VISENTINI, 2013; LECHINI, 2008).

No entanto, foi durante o governo Collor de Melo (1990-1992) que houve uma inflexão significativa em relação à África. O neoliberalismo econômico adotado por Collor de Melo privilegiava as relações NorteSul em detrimento das relações Sul-Sul. Assim,

A política africana perdeu força e se acentuou seu caráter seletivo, às vezes encoberto pelo recurso da diplomacia cultural. As relações bilaterais começaram a se concentrar naqueles países que tinham condições de responder às necessidades brasileiras. A cooperação Sul-Sul das décadas de 70 e 80 deu lugar às "associações estratégicas". O foco se centrou em poucos países e temas. Observou-se uma importância crescente da África do Sul- já democrática-, de Angola e da Nigéria. No âmbito multilateral, fomentou a cooperação com os países da Comunidade para o desenvolvimento da África Austral (SADC) sob o guarda-chuva do Mercosul, também com a Comunidade dos Países de Língua Portuguesa (CPLP) e com a Zona de Paz e Cooperação do Atlântico Sul ${ }^{6}$ (ZPCAS) (LECHINI, 2008, p.63).

As relações afro-brasileiras não tiveram um papel de destaque na política externa brasileira por toda a década de 1990 e início dos anos 2000. Houve declínio comercial, diminuição do número de diplomatas brasileiros na África e perda do status da África dentro do Itamaraty (VISENTINI, 2013). O baixo perfil das relações afro-brasileiras no período, no entanto, não representou uma ruptura com o outro lado do Atlântico, "foram selecionados países-chave como prioritários e neles concentrados esforços limitados" (VISENTINI, 2013, p.92).

Durante a primeira metade do governo Fernando Henrique Cardoso (1994-2002), o continente africano continuou não sendo um parceiro prioritário. A aproximação com o Terceiro Mundo era considerada obsoleta e anacrônica, além de não representar ganhos significativos dentro do ideário neoliberal adotado por FHC (LECHINI, 2008). No entanto, durante a segunda metade do governo FHC é possível notar uma inflexão na política brasileira para a África. Dentro do contexto da crise do Real e do discurso de crítica à "globalização

\footnotetext{
${ }^{5}$ Em 1983, João Baptista Figueiredo fez a primeira visita oficial de um presidente brasileiro e sul-americano ao continente africano. Nessa viagem foram visitados países lusófonos, francófonos e anglófonos, sendo eles: Nigéria, Senegal, Guiné-Bissau, Cabo Verde e Argélia (VISENTINI, 2013 E LECHINI, 2008).

${ }^{6}$ A Zona e Paz e Cooperação do Atlântico Sul (ZOPACAS) foi estabelecida em 1986, por meio da Resolução 41/11 da Assembleia Geral das Nações Unidas. É integrada por 24 países banhados pelo Atlântico Sul: África do Sul, Angola, Argentina, Benin, Brasil, Cabo Verde, Camarões, Congo, Costa do Marfim, Gabão, Gâmbia, Gana, Guiné-Conacri, Guiné-Bissau, Guiné-Equatorial, Libéria, Namíbia, Nigéria, República Democrática do Congo, São Tomé e Príncipe, Senegal, Serra Leoa, Togo e Uruguai (Fonte: Itamaraty.gov.br).
} 
assimétrica” sustentado por FHC, há a busca da reaproximação com os Estados africanos com o objetivo de garantir maior convergência em foros multilaterais e econômicos (VISENTINI, 2013).

Se, no fim dos anos 1990 e início dos anos 2000, a crise do Real, do Mercosul e o esgotamento da matriz neoliberal adotada por FHC impactaram no modelo de inserção internacional do Brasil, demandando um novo debate sobre a política externa em vigor, levando a buscar uma nova estratégia de inserção internacional do Brasil nesse período (SILVA, A. 2009), do outro lado do Atlântico, o continente africano passava também por uma nova fase, um "renascimento". A diminuição do custo África ${ }^{7}$ no início dos anos 2000 transformou o continente em uma importante fronteira de investimentos, transformando-o em um polo de atração de investimento direto, especialmente na indústria extrativa e de infraestrutura relacionada ao escoamento da produção de recursos naturais minerais, causado pelo aumento do preço desse tipo de recurso no mercado internacional (IGLESIAS E COSTA, 2012).

\section{A política externa de Lula da Silva: autonomia pela diversificação.}

A chegada de Lula da Silva à presidência do Brasil em 2003 acelerou e aprofundou o processo de aproximação com países do continente africano iniciado por Cardoso. Em oposição à orientação bilateral da política externa brasileira da década de 1990, o governo Lula adotou uma orientação globalista de eixos combinados que buscava fortalecer tanto o eixo horizontal das relações internacionais brasileiras - por meio do estreitamento das relações terceiro-mundista, também chamado de cooperação Sul-Sul; quanto do eixo vertical por meio da ampliação de sua margem de manobra e poder de barganha adquirido a partir da diversificação de seus parceiros frente aos países desenvolvidos (eixo Norte-Sul). Assim, há o incremento das relações brasileiras tanto com países emergentes como China, Rússia, África do Sul e Índia quanto com países menos desenvolvidos da África, Ásia e Oriente Médio (PECEQUILO, 2008).

De acordo com Cervo (2011), a política externa de Lula é caracterizada por uma mudança de paradigma de inserção internacional. Há o abandono do paradigma neoliberal adotado durante os anos 1990 e a adoção do paradigma logístico, semelhante, em alguns aspectos, ao paradigma desenvolvimentista dos anos 1970.

\footnotetext{
Logístico é aquele Estado que não se reduz a prestar serviço, com fazia à época do desenvolvimentismo, nem a assistir passivamente às forças do mercado e do poder hegemônico, como se portava à época do neoliberalismo. Logístico porque recupera o planejamento estratégico do desenvolvimento e exerce a função de apoio e legitimação das iniciativas de outros atores econômicos e sociais, aos quais repassa responsabilidade e poder. [...] Como tudo isso depende do interno e do externo, o Estado entra com o peso do nacional sobre a política exterior e torna-se agente da governança global. Ao colocar a estratégia a serviço do desenvolvimento, faz nascer o Estado logístico, cuja conduta se diferencia, como se vê, daquela do Estado neoliberal, especialmente ao recuperar a autonomia decisória na esfera política e ao voltar-se para o reforço do núcleo duro da economia nacional. (CERVO, 2011, p.529-560).
}

Cervo (2011, p.529) aponta três causalidades que colaboraram para a consolidação do Estado logístico de Lula.

\footnotetext{
${ }^{7}$ O custo África está relacionado, Segundo Lechini (2008, p.63), “à recorrente instabilidade política e econômica da maior parte dos países da região, que levou muitos países africanos a se afastar das rotas de capitais e a não pagar suas dívidas.”
} 
$>\quad$ A sociedade encontra-se em nível avançado de organização, com suas federações de classe articulando industriais, agricultores, banqueiros, operários, comerciantes e consumidores, condição que facilita a função de coordenação superior do Estado guiado pelo interesse nacional, soma dos interesses setoriais;

$>\quad$ A estabilidade política e econômica, que sugere associar a lógica da governabilidade interna com a lógica da governança global;

$>\quad$ O nível avançado dos agentes econômicos e sociais em termos de organização empresarial e competitividade sistêmica.

Ainda de acordo com Cervo (2011), o Brasil tem buscado tornar-se um país globalista no século XXI. O modelo de inserção internacional adotado pelo Brasil é, segundo o autor, o globalismo industrialista, caracterizado por dois traços essenciais: o multilateralismo da reciprocidade e a internacionalização econômica. O multilateralismo da reciprocidade é caracterizado por dois pressupostos,

A existência de regras para compor o ordenamento internacional, sem as quais irá prevalecer a disparidade de poder em benefício das grandes potências; e a elaboração conjunta dessas regras, de modo a garantir reciprocidade de efeitos para que não realizem interesses de uns em detrimento de outros (CERVO, 2011, p.531).

Enquanto Cervo analisa as mudanças na política externa de Lula sob a perspectiva da mudança de paradigma, Vigevani e Cepaluni (2007) as analisam com base no modelo de análise das mudanças de política externa desenvolvido por Hermann ${ }^{8}$. Os autores sustentam que as mudanças na política externa de Lula já estavam em curso desde o final do governo de Fernando Henrique Cardoso e são caracterizadas pela "mudança de ênfase e de tonalidade em sua política externa (ajustes), buscando novas formas de inserção internacional para o país (mudança de programa)" (VIGEVANI E CEPALUNI, 2007, p.282) e que "o acúmulo de mudanças de programa, sem a pretensão de provocar mudanças de orientação internacional, leva a mudanças substantivas, sem rupturas radicais” (VIGEVANI E CEPALUNI, 2007, p.295).

A política externa de FHC defendia a ideia da "autonomia pela participação" no sistema internacional, contrapondo-se à busca da "autonomia pela distância ${ }^{10 "}$ que prevaleceu até o fim do governo Sarney, enquanto Lula da Silva procurou inserir o Brasil no cenário mundial acentuando formas autônomas, diversificando os parceiros e as opções estratégicas brasileiras. Apesar de existirem elementos de alteração dos rumos do país ainda na administração FHC, Lula da Silva utiliza uma estratégia que poderia ser batizada de "autonomia pela diversificação", enfatizando a cooperação Sul-Sul para buscar maior equilíbrio com os países do Norte, realizando ajustes, aumentando o protagonismo internacional do país e consolidando mudanças de programa na política externa (VIGEVANI E CEPALUNI, 2007, p.282-283).

A autonomia pela diversificação adotada durante o governo Lula utiliza as alianças Sul-Sul e acordos com parceiros não tradicionais como China, Oriente Médio, África, Ásia-Pacífico, Europa Oriental, dentre

\footnotetext{
${ }^{8}$ HERMANN, Charles F. Changing Course: When Governments Choose to Redirect Foreign Policy. International Studies Quarterly, vol. 34, $\mathrm{n}^{\circ} 1$ (Mar. 1990), 3-21.

${ }^{9}$ A autonomia pela participação pode ser entendida como "a adesão aos regimes internacionais, inclusive os de cunho liberal, sem a perda da capacidade de gestão da política externa; nesse caso, o objetivo seria influenciar a própria formulação dos princípios e das regras que regem o sistema internacional” (VIGEVANI E CEPALUNI, 2007, p.283).

${ }^{10}$ A autonomia pela distância é definida como "uma política de não-aceitação automática dos regimes internacionais prevalecentes e, sobretudo, a crença no desenvolvimento parcialmente autárquico, voltado para a ênfase no mercado interno; consequentemente, uma diplomacia que se contrapõe a certos aspectos da agenda das grandes potências para se preservar a soberania do Estado Nacional” (VIGEVANI E CEPALUNI, 2007, p.283).
} 
outros, para reduzir as assimetrias nas relações externas com países mais poderosos, além de aumentar o poder de barganha brasileiro frente aos países do Norte (VIGEVANI E CEPALUNI, 2007). Ainda de acordo com Vigevani e Cepaluni (2007), é possível notar algumas diretrizes na mudança de política externa de Lula,

\footnotetext{
$>\quad$ Contribuir para o busca de maior equilíbrio internacional, procurando atenuar o unilateralismo; > Fortalecer relações bilaterais e multilaterais de forma a aumentar o peso do país nas negociações políticas e econômicas internacionais;

> Adensar as relações diplomáticas no sentido de aproveitar as possibilidades de maior intercâmbio econômico, financeiro e tecnológico, cultural e etc;

$>\quad$ Evitar acordos que possam comprometer em longo prazo o desenvolvimento.
}

Um dos desdobramentos das diretrizes adotadas na reorientação da política externa brasileira durante o governo Lula foi a reaproximação e o aprofundamento das relações com os países africanos e do Sul em geral. Já em seu discurso de posse do primeiro mandato, Lula reafirmou os laços com o continente africano e a disposição em contribuir para que ele desenvolva suas potencialidades, indicando a importância da reaproximação com o continente africano (SILVA, L. 2003) e, em seu discurso de posse do segundo mandato destacou a proximidade com o continente africano conquistada durante os primeiros quatro anos de governo (SILVA, L. 2007). Essa mudança se deve a uma “maior compreensão do governo da importância do apoio africano para aumentar a projeção do Brasil no cenário internacional, na sua estratégia de se inserir globalmente, cumprindo sua aspiração como uma potência de porte médio" (VISENTINI, 2013, p.95).

Dentre os fatores indicativos do fortalecimento da posição da África na política externa brasileira, podemos citar a reestruturação institucional do Itamaraty durante o primeiro ano de mandato de Lula (em que foram criadas duas divisões específicas para o continente - Divisão África I e II, além do desmembramento do antigo Departamento da África e Oriente Médio, dando lugar a Divisão África III), o elevado número visitas presidências ao longo dos oito anos de governo de Luiz Inácio Lula da Silva, o crescimento do número de parceiros $^{11}$ e do orçamento ${ }^{12}$ de cooperação Sul-Sul entre o Brasil e países africanos, o crescimento significativo do número de empresas brasileiras em países africanos, bem como do volume de comércio entre o Brasil e países desse continente, a reabertura de postos diplomáticos brasileiros em países africanos e o perdão de dívidas de países do referido continente (VISENTINI, 2013; LECHINI, 2008).

Desde o ano de 2003 o continente africano tem recebido um número significativo de projetos e atividades de cooperação Sul-Sul oferecidos pelo Brasil. O gráfico.1, disponibilizado pela Agência Brasileira de Cooperação, mostra com clareza a evolução do número de projetos e ações de cooperação, bem como o crescimento expressivo do orçamento desse tipo de ação, já o gráfico. 2, explicita a variedade de segmentos de cooperação estabelecido entre os dois lados do Atlântico.

\footnotetext{
${ }^{11}$ De acordo com a Agência Brasileira de Cooperação $(\mathrm{ABC})$, os parceiros africanos são: África do Sul, Angola, Argélia, Benin, Botsuana, Burkina Faso, Burundi, Cabo verde, Camarões, Chade, Costa do Marfim, Egito, Gabão, Gâmbia, Gana, Guiné Bissau, Guiné Equatorial, Lesoto, Libéria, Madagascar, Malauí, Mali, Marrocos, Mauritânia, Moçambique, Namíbia, Nigéria, Quênia, República Democrática do Congo, República do Congo, Ruanda, São Tomé e Príncipe, Seicheles, Senegal, Serra Leoa, Sudão, Tanzânia, Togo, Tunísia, Uganda, Zâmbia e Zimbábue.

${ }^{12}$ De acordo com a Agência Brasileira de Cooperação, o orçamento de cooperação Sul-Sul com países africanos passou de $\$ 497.668$,00 em 2003 para \$19.844.882,00 em 2010. Porém, a moeda utilizada não é especificada.
} 
Gráfico 1: Execução financeira cooperação Sul-Sul (2000-2014).

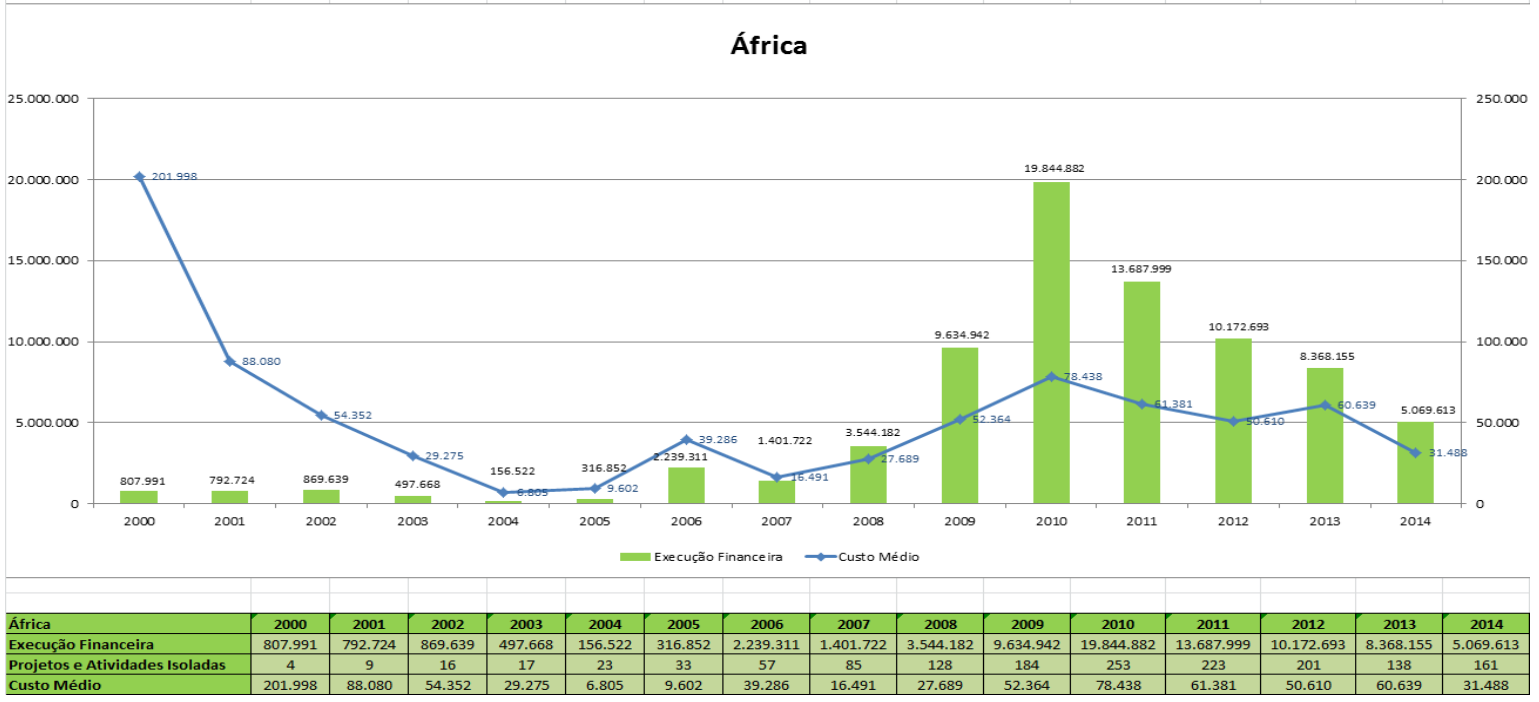

Fonte: Agência Brasileira de Cooperação.

Gráfico 2: Cooperação Sul-Sul (Brasil- África) por segmento.

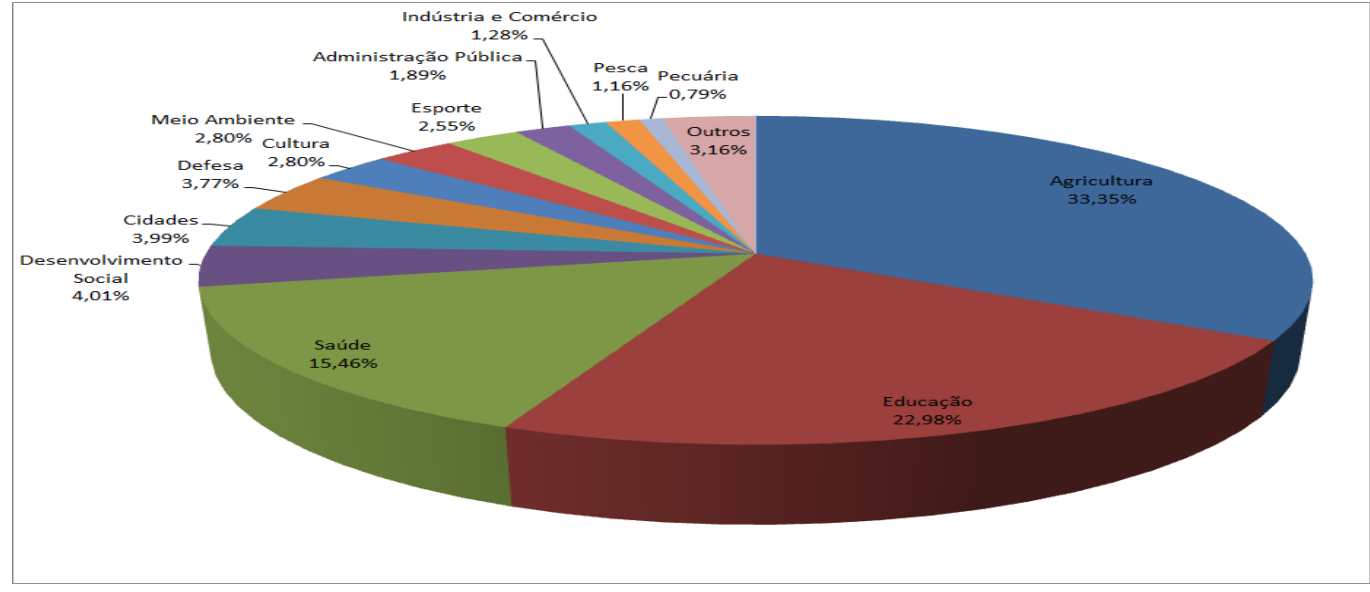

Fonte: Agência Brasileira de Cooperação.

A significativa participação dos segmentos da agricultura e da saúde no âmbito da cooperação Sul-Sul oferecida pelo Brasil a países africanos está intimamente relacionada ao discurso humanitário de combate a fome e as epidemias (especialmente o HIV-AIDS) endossado por Lula tanto no plano interno quanto externo. O oferecimento de tecnologias de saúde e agricultura melhor adaptadas à realidade do continente, aliado ao discurso humanitário, levou aos parceiros africanos elementos distintos dos oferecidos por outros parceiros internacionais como China, Índia e Estados Unidos (OLIVEIRA, 2015). O segmento da educação, com participação 22,98\% nas ações, reflete o incremento nos projetos de cooperação como o PEC-G, PEC-PG e Unilab.

O elevado número de viagens presidenciais feitas por Lula ao continente africano também é um aspecto importante da posição africana na política externa brasileira. Em novembro de 2003 Lula fez a sua 
primeira viagem ao continente, visitando São Tomé e Príncipe, Angola, Moçambique, Namíbia e África do Sul. Em dezembro do mesmo ano, em uma viagem a países árabes, Lula visitou Líbia e Egito (BRASIL, 2003). Em julho de 2004 Lula visitou São Tomé e Príncipe, Gabão e Cabo Verde, sendo a única viagem do presidente ao continente naquele ano (BRASIL, 2004). No ano de 2005, Lula visitou Camarões, Nigéria, Gana, Guiné-Bissau e Senegal (BRASIL, 2005). Em mais uma viagem ao continente em 2006, Lula visitou a Argélia, Benin, Botsuana, África do Sul e Nigéria (BRASIL, 2006). Em 2007, Burkina Faso, República do Congo, África do Sul e Angola (BRASIL, 2007). Em 2008, Gana foi o único país africano visitado (BRASIL, 2008), em 2009 a Líbia (BRASIL, 2009). Em 2010, no entanto, o então presidente Lula visitou o continente duas vezes, durante a primeira visita foi a Cabo Verde, Guiné Equatorial, Quênia, Tanzânia, Zâmbia e África do Sul. Já na segunda, a Moçambique (BRASIL, 2010).

Além do grande número de visitas oficiais e de Estado feitas por Lula a líderes africanos, houveram diversas reuniões e encontros com líderes africanos em oportunidades de outras viagens internacionais feitas por Lula e diversas visitas de líderes e chanceleres africanos ao Brasil (BRASIL, 2003; BRASIL, 2004; BRASIL, 2005; BRASIL, 2006; BRASIL, 2007; BRASIL, 2008; BRASIL, 2009; BRASIL, 2010; LECHINI, 2008), evidenciando assim, o intenso diálogo entre o líder brasileiro e os líderes africanos. É importante ressaltar, também, que grande parte das viagens feitas por Lula à países africanos estavam relacionados a encontros de foros multilaterais como IBAS e CPLP (BRASIL, 2003; BRASIL, 2004; BRASIL, 2005; BRASIL, 2006; BRASIL, 2007; BRASIL, 2008; BRASIL, 2009; BRASIL, 2010). Os foros multilaterais de diálogo entre Brasil e África tiveram especial destaque durante o governo Lula. Houve o relançamento da Zopacas, a realização das Cúpulas América do Sul-África ${ }^{13}$ (OLIVEIRA, 2015) e a intensificação das relações com os PALOPS ${ }^{14}$ (VISENTINI, 2013).

As visitas presidenciais de Lula tinham frequentemente o perfil de missões empresariais, no qual o presidente era acompanhado ao exterior por diversos empresários interessados na internacionalização de suas empresas.

\footnotetext{
As empresas brasileiras também tiveram um papel importante durante o Governo Lula, pois, para fortalecer os laços com os países africanos, foram substancialmente favorecidas pela política diplomática presidencial. Um bom sinal disso foi o aumento de missões empresariais durante o governo Lula, resultando num crescente número de empresas brasileiras - especialmente aquelas que exportam serviços- no continente africano: entre essas iniciativas brasileiras é importante citar a presença ativa da Vale, da Petrobras e da Odebrecht (VISENTINI, 2013, P.98).
}

As relações comerciais entre o Brasil e países africanos também passou por um significativo aprofundamento após 2003. Houve um significativo e progressivo incremento das trocas comerciais entre os dois lados do Atlântico. De acordo com Lechini (2008), o comércio Brasil-África passou de US\$ 5 bilhões em 2002 para quase US\$20 bilhões em 2007. O continente africano também se tornou uma importante fronteira

\footnotetext{
${ }^{13}$ ASA é fruto da iniciativa do governo brasileiro e nigeriano de aproximar as duas regiões. Com reuniões a cada dois ou três anos, a ASA reúne 66 líderes e chefes de Estado (12 sul-americanos e 54 africanos), que buscam construir plataformas de diálogo político e cooperação entre as duas regiões. (ITAMARATY, BRASIL)

${ }^{14}$ PALOPS é a sigla comumente utilizada para designar os países africanos de língua oficial portuguesa, Angola, Moçambique, GuinéBissau, Cabo Verde, São Tomé e Príncipe, e, recentemente, Guiné Equatorial.
} 
para a internacionalização de empresas brasileiras, tendo "se destacado como a terceira região com maior índice de crescimento de regionalidade das transnacionais brasileiras, com 16,39\%" (VILAS-BÔAS, 2011, p 3).

Mapeando os investimentos brasileiros na África, foram identificados 22 países nos quais existem empresas brasileiras, sendo os setores de minerais e construção civil os mais consolidados e o das pequenas e médias empresas e franquias os com maior potencial para o futuro. O setor de serviços se destaca, mas este é mais forte onde os investimentos em outras áreas são mais significativos (VILASBÔAS, 2011, p 4).

\section{A política externa de Dilma Rousseff para a África.}

A chegada de Dilma Rousseff à chefia do poder executivo federal em 2011 emanou diversas expectativas quanto a mudanças ou continuidades na política externa traçada durante o governo Lula, em especial] devido à troca do Ministro das Relações Exteriores Celso Amorim por Antônio Patriota (OLIVEIRA, 2015). Nota-se no governo Rousseff uma continuidade das diretrizes gerais da política externa brasileira em curso desde 2003. Porém, é inegável a diminuição de intensidade entre a diplomacia presidencial praticada por Lula e Dilma. Cervo e Lessa (2014) caracterizam o governo Rousseff com declínio da política externa brasileira em contraposição a ascensão alcançada durante os oito anos de governo de seu antecessor.

Ainda que o governo Rousseff possua as fragilidades apontadas por Cervo e Lessa (2014), a saber, a não formulação de uma política de comércio exterior; não programação, junto aos empresários, de uma estratégia de inovação exigida pela competitividade sistêmica de economias internacionalizadas; insuficiente infraestrutura e elevada carga tributária interna; diminuição significativa do diálogo com o empresariado industrial e do agronegócio, bem como com dirigentes de seu governo e dificuldade em articular a política de Estado com universidades, centros de pesquisas e empresariado para inovação tecnológica, causando baixa inovação e baixa competitividade internacional, vale ressaltar que o contexto interno e externo do governo Dilma em muito difere do contexto em que se situava o governo Lula.

Os efeitos secundários da crise internacional de 2008 começaram a atingir com mais força os países em desenvolvimento a partir de 2011, causando desaceleração e retração de economias emergentes, em especial a brasileira e paralização do sistema internacional. Além das dificuldades relacionadas ao sistema internacional, Dilma Rousseff também enfrenta, especialmente durante o fim do seu primeiro e início do segundo mandato, dificuldades de articulação e diálogo com o poder legislativo, o que tem causado a paralisia de seu governo em questões importantes.

Além da conjuntura interna delicada e contexto internacional desfavorável, nota-se durante o governo Rousseff um distanciamento da presidente em relação a questões internacionais, que se torna especialmente destacado após dezesseis anos de intensa diplomacia presidencial promovido por Cardoso e Lula. Com um número de viagens internacionais muito inferior ao de seus antecessores, Dilma visitou o continente africano cinco vezes durante os quatro anos de seu primeiro mandato, no entanto, o nota-se o baixo número de países visitado, sendo eles, África do Sul (três vezes, sendo uma delas na ocasião do funeral do líder sul-africano Nelson Mandela), Moçambique, Angola, Guiné Equatorial, Nigéria e Etiópia apenas uma vez cada (BRASIL, 2015). 
No tocante a cooperação Sul-Sul, é notória a redução da execução financeira da mesma. Desde 2011 o montante aplicado neste tipo de ação tem diminuído consideravelmente. Enquanto teve seu pico em 2010, atingindo a marca de $\$ 19.884 .882$, em 2014 , o montante foi de $\$ 5.069 .613$ (ver gráfico.1) . Porém, a redução na verba e na execução financeira da cooperação Sul-Sul não foi apenas destinada a África e sim uma redução geral no orçamento dessas ações que passou de $\$ 37.819 .613$ em 2010, quando atingiu seu pico, para \$7.099.064 em 2014 (AGÊNCIA BRASILEIRA DE COOPERAÇÃO, 2015). No entanto, é importante ressaltar que mesmo com as sucessivas reduções de execução orçamentária no período compreendido entre 2011 e 2014, o continente africano continua sendo o principal recebedor ${ }^{15}$ da cooperação Sul-Sul em volumes financeiros, com aproximadamente $71,41 \%$ do orçamento total da cooperação Sul-Sul prestada pelo Brasil, além de ter as ações com preço médio mais elevado dentre todas as regiões parceiras do Brasil.

Mesmo com o baixo número de visitas presidenciais ao continente africano feitas por Dilma Rousseff, o número de projetos de cooperação firmados com países africanos continua a crescer. De acordo com Oliveira (2015), em 2011 foram firmados 81 novos projetos de cooperação com países africanos e em 2012, 37 ${ }^{16}$. Assim, a diminuição significativa do número de visitas oficiais da presidente ao continente africano não significou uma ruptura com a política africana desenvolvida por Lula da Silva, mesmo com as dificuldades econômicas e políticas enfrentadas por Rousseff no período.

Houve ainda a manutenção do tipo de projetos de cooperação, dando especial importância ao que a Agência Brasileira de Cooperação denomina "projetos estruturantes”, ou seja, projetos que "visam a criação e a estruturação de instituições para capacitação de mão-de-obra em áreas deficientes nos países que demandam essa cooperação" (AGÊNCIA BRASILEIRA DE COOPERAÇÃO, 2015), e cooperação em áreas humanitárias como saúde e agricultura.

A diminuição do envolvimento direto da presidente Dilma em assuntos de política externa, ao contrário do que aconteceu durante os governos de seus antecessores que foram fortemente marcados pelo envolvimento do presidente em assuntos de política externa, "foi um dos principais motivos para que se criasse uma ideia de que o continente [africano] teria menos espaço - e importância - na política externa brasileira" (OLIVEIRA, 2015, p.40).

Diante do exposto, o governo Rousseff não pode ser considerado um novo período de afastamento nas relações afro-brasileiras, uma vez que houve uma alteração na forma de condução da política africana, agora com menos envolvimento direto da chefe do executivo federal do que durante o governo Lula, e não uma mudança de prioridade nos relacionamentos entre o Brasil e seus parceiros no continente africano. Cabe ainda destacar que os períodos de afastamento nos relacionamentos afro-brasileiros estão inseridos na lógica de priorização dos relacionamentos Norte-Sul em detrimento ao relacionamento Sul-Sul, o que não se verificou durante o período do primeiro mandato de Dilma Rousseff.

\footnotetext{
${ }^{15}$ Em número de ações o continente africano fica em segundo lugar, atrás apenas das Américas e Caribe, no entanto, considerando o custo médio das ações e o volume de recursos aplicados, o continente africano figura como o principal recebedor de cooperação SulSul oferecida pelo Brasil.

${ }^{16}$ Ao analisar o número de projetos, também deve ser levado em consideração a duração dos mesmos, uma vez que podem ser ações pontuais e de curta duração, bem como ações de médio prazo levando alguns anos para a sua finalização.
} 


\section{Conclusão}

Diante do demonstrado ao decorrer do presente artigo, confirma-se a hipótese do fortalecimento e consolidação do continente africano em uma posição de destaque dentro da política externa brasileira após 2003. O incremento significativo das relações comerciais entre os dois lados do Atlântico, a diversificação de parceiros, o aumento do número de empresas brasileiras no continente africano, o grande número de ações e projetos de cooperação, dentre outros, apontam para um estreitamento e aprofundamento das relações afrobrasileiras e a consolidação da África em uma posição de relevância dentro da política externa brasileira.

Muito foi produzido sobre a política externa brasileira para a África durante o governo Lula, porém o mesmo esforço não tem sido dedicado ao governo Rousseff. Apesar do perfil "lerdo" e de "declínio", como denominam Cervo e Lessa (2014), da política externa de Dilma, esta não apresenta uma ruptura na política africana do Brasil nem a depreciação da posição africana dentro da política externa brasileira. Nota-se, no entanto, uma diminuição geral da intensidade da política externa praticada por Dilma em relação a política externa praticada por Lula, porém, esta diminuição de intensidade não significa um reordenamento de política externa.

Após um período de mais de uma década de reaproximação com o continente africano e busca de projeção internacional do Brasil baseada na diversificação de parceiros e consolidação de sua posição como país emergente, as relações afro-brasileiras alcançam hoje um novo patamar e podemos dizer que este é um novo "período de ouro" da política externa africana do Brasil.

Ainda que muitos países do continente africano apresentem entraves ao investimento estrangeiro, como falta de uma legislação clara sobre esse tipo de investimento e baixa estabilidade institucional, e que não haja convergência automática entre cooperação e capital diplomático investido com investimento privado, as transformações por que têm passado diversos países do continente desde o início dos anos 2000, ainda representam uma fronteira aberta para a expansão de negócios brasileiros. Uma prova disso são os frutos positivos das missões empresariais promovidas pelo governo brasileiro ao continente africano.

\section{REFERÊNCIAS}

AGÊNCIA BRASILEIRA DE COOPERAÇÃO. África - Execução Financeira (2000 - 2014). Disponível em: http://www.abc.gov.br/Gestao/AfricaExecucaoFinanceira

AGÊNCIA

BRASILEIRA

$\mathrm{DE}$ COOPERAÇÃO.

Quantitativos de Projetos e Atividades Isoladas de Cooperação por Ano. Disponível em: http://www.abc.gov.br/Gestao/QuantitativoProjetos

AGÊNCIA BRASILEIRA DE COOPERAÇÃO. Países Parceiros da Cooperação Sul-Sul Brasileira. Disponível em: http://www.abc.gov.br/Gestao/PaisesParceiros

AGÊNCIA BRASILEIRA DE COOPERAÇÃO. Evolução da Execução Financeira dos Projetos da ABC. Disponível em: http://www.abc.gov.br/Gestao/EvolucaoFinanceira

AGÊNCIA BRASILEIRA DE COOPERAÇÃO. África - Por Segmento de Cooperação (2000-2014). Disponível em: http://www.abc.gov.br/Gestao/AfricaSegmentoCooperacao 
BRASIL, Viagens presidenciais internacionais Luiz Inácio Lula da Silva $-1^{\circ}$ mandato, ano 2003. Biblioteca da Presidência da República, 2003. Disponível em: http://www.biblioteca.presidencia.gov.br/expresidentes/luiz-inacio-lula-da-silva/viagens/viagens-internacionais-1o-mandato/viagensinternacionais-2003.pdf/view

BRASIL, Viagens presidenciais internacionais Luiz Inácio Lula da Silva $-1^{\circ}$ mandato, ano 2004. Biblioteca da Presidência da República, 2004. Disponível em: http://www.biblioteca.presidencia.gov.br/expresidentes/luiz-inacio-lula-da-silva/viagens/viagens-internacionais-1o-mandato/viagensinternacionais-2004.pdf/view

BRASIL, Viagens presidenciais internacionais Luiz Inácio Lula da Silva $-1^{\circ}$ mandato, ano 2005 . Biblioteca da Presidência da República, 2005. Disponível em: http://www.biblioteca.presidencia.gov.br/expresidentes/luiz-inacio-lula-da-silva/viagens/viagens-internacionais-1o-mandato/viagensinternacionais-2005.pdf/view

BRASIL, Viagens presidenciais internacionais Luiz Inácio Lula da Silva $-1^{\circ}$ mandato, ano 2006. Biblioteca da Presidência da República, 2006. Disponível em: http://www.biblioteca.presidencia.gov.br/expresidentes/luiz-inacio-lula-da-silva/viagens/viagens-internacionais-10-mandato/viagensinternacionais-2006.pdf/view

BRASIL, Viagens presidenciais internacionais Luiz Inácio Lula da Silva $-2^{\circ}$ mandato, ano 2007. Biblioteca da Presidência da República, 2007. Disponível em: http://www.biblioteca.presidencia.gov.br/expresidentes/luiz-inacio-lula-da-silva/viagens/viagens-internacionais-2o-mandato/viagensinternacionais-2007.pdf/view

BRASIL, Viagens presidenciais internacionais Luiz Inácio Lula da Silva $-2^{\circ}$ mandato, ano 2008 . Biblioteca da Presidência da República, 2008. Disponível em: http://www.biblioteca.presidencia.gov.br/expresidentes/luiz-inacio-lula-da-silva/viagens/viagens-internacionais-2o-mandato/viagensinternacionais-2008.pdf/view

BRASIL, Viagens presidenciais internacionais Luiz Inácio Lula da Silva $-2^{\circ}$ mandato, ano 2009. Biblioteca da $\begin{array}{lllll}\text { Presidência da } & \text { República, } & 2009 . & \text { Disponível }\end{array}$ http://www.biblioteca.presidencia.gov.br/presidencia/ex-presidentes/luiz-inacio-lula-dasilva/viagens/viagens-internacionais-2o-mandato/viagens-internacionais-2009.pdf/view

BRASIL, Viagens presidenciais internacionais Luiz Inácio Lula da Silva $-2^{\circ}$ mandato, ano 2010 . Biblioteca da Presidência da $\quad 2010 . \quad$ República, Disponível em: http://www.biblioteca.presidencia.gov.br/presidencia/ex-presidentes/luiz-inacio-lula-dasilva/viagens/viagens-internacionais-2o-mandato/viagens-internacionais-2010/view

BRASIL, Viagens presidenciais Dilma Rousseff $-1^{\circ}$ mandato. Biblioteca da Presidência da República. Disponível: http://www.biblioteca.presidencia.gov.br/presidente-atual/viagens

CERVO, Amado Luiz; BUENO, Clodoaldo. História da política exterior do Brasil. -4. Ed. rev. ampl.- Brasília, Editora universidade de Brasília, 2011.

CERVO, Amado Luiz, LESSA, Antônio Carlos. O declínio: inserção internacional do Brasil (2011-2014). Revista Brasileira de Política Internacional. 57 (2), p 133-151, 2014.

IGLESIAS, Roberto; COSTA, Catarina. O investimento direto brasileiro na África: características, condicionantes e perspectivas. Pontes, Abril/Maio 2012 Vol.8 No.2. Disponível em: http://www.ictsd.org/sites/default/files/review/pontes/pontes8-2.pdf

LECHINI, Gladys. O Brasil na África ou a África no Brasil? A construção da política africana pelo Itamaraty. Nueva Sociedad especial em português, outubro de 2008, p.55-71. Disponível em: http://www.cebri.org/midia/documentos/318.pdf 
OLIVEIRA, Guilherme Ziebell, Política Africana do Brasil: mudanças entre Lula e Dilma? Conjuntura Austral, Porto Alegre, V.6, N.29, abril-maio 2015, p. 29-47.

PECEQUILO, Cristina Soreanu. A Política Externa do Brasil no Século XXI: Os Eixos Combinados de Cooperação Horizontal e Vertical. Revista Brasileira de Política Internacional. Vol. 51, n. 2, 2008, p.136-153.

PENNA FILHO, Pio; LESSA, Antônio Carlos Moraes. O Itamaraty e a África: as origens da política africana do Brasil. Estudos históricos, Rio de Janeiro, n³9, janeiro-junho de 2007, p.57-81.

SILVA, André Luiz Reis. Do otimismo liberal à globalização assimétrica: A política externa do governo Fernando Henrique Cardoso (1995-2002). Curitiba: Juruá, 2009

SILVA, Luiz Inácio Lula da. Pronunciamento do Presidente da República, Luiz Inácio Lula da Silva, na sessão solene de posse no Congresso Nacional Brasília - DF, 01 de janeiro de 2003. Biblioteca da Presidência da República, 2003.

SILVA, Luiz Inácio Lula da. Pronunciamento à nação do Presidente da República, Luiz Inácio Lula da Silva, na cerimônia de posse Palácio do Planalto, $1^{\circ}$ de janeiro de 2007. Biblioteca da Presidência da República, 2007.

VILAS-BÔAS, Júlia Cover. Os investimentos brasileiros na África no governo Lula: um mapa. Meridiano 47, Brasília, V. 12, N. 128, nov-dez, 2011, p.3-9.

VIGEVANI, Tullo; CEPALUNI, Gabriel. A política externa de Lula da Silva: a estratégia da autonomia pela diversificação. Rio de Janeiro. Contexto Internacional, vol. 29, n² 2, julho/dezembro 2007, p. 273-335.

VISENTINI, Paulo. O Brasil reencontra o caminho africano. In: A África e as potências emergentes: nova partilha ou cooperação Sul-Sul. Porto Alegre, Leitura XXI, 2013, p. 81-152. 


\title{
RESUMO
}

O início do governo Lula em 2003 marcou o aprofundamento e a aceleração de um processo que começou a se delinear durante o segundo mandato de Fernando Henrique Cardoso. A nova política externa brasileira de perfil globalista, em oposição à política externa bilateral e alinhada com os Estados Unidos dos anos 1990, visou a projeção internacional do Brasil como país emergente e a diversificação de parceiros, especialmente no Sul. O crescente peso diplomático e econômico adquirido pelo continente africano nas relações exteriores do Brasil após 2003 demostra uma inflexão da política externa brasileira para seus parceiros do Sul, em detrimento do afastamento e seletividade da década de 1990. O presente artigo tem por objetivo analisar o lugar das relações afro-brasileiras dentro da política externa dos presidentes Lula da Silva e Dilma Rousseff. A hipótese sustentada é que o continente africano representa uma importante fronteira comercial e diplomática para o Brasil e que, por essa razão teve sua posição fortalecida dentro no espectro de parceiros brasileiros. Para tanto, serão analisadas as relações diplomáticas, de cooperação e comerciais no período compreendido entre o primeiro mandato de Luiz Inácio Lula da Silva em 2003 e o fim do primeiro mandato de Dilma Rousseff em 2014.

Palavras-chave: Política externa brasileira; África; governo Lula; Governo Dilma Rousseff.

\begin{abstract}
The beginning of the Lula's administration in 2003 marked the deepening and acceleration of a process that began to emerge during the Fernando Henrique Cardoso's second-term. The new Brazilian foreign policy globalist profile, as opposed to bilateral foreign policy and aligned with the United States in the 1990s, aimed at international recognition of Brazil as an emerging country and diversification of partners, especially in the South. The growing diplomatic and economic weight acquired the African continent in foreign relations of Brazil after 2003 demonstrates a shift of Brazil's foreign policy to its Southern partners at the expense of removal and selectivity of the 1990s. This article aims to analyze the place of Afro-Brazilian relations within the foreign policy of Lula da Silva and Dilma Rousseff. Sustained hypothesis is that Africa is an important commercial and diplomatic frontier for Brazil and for that reason had strengthened its position within the spectrum of Brazilian partners. For this, cooperation and diplomatic relations will be reviewed in the period from the Luiz Inacio Lula da Silva's first term in 2003 to the end of the Dilma Rousseff's first term in 2014.
\end{abstract}

Key words: Brazilian foreign policy; Africa; Lula administration; Dilma Rousseff administration. 